\title{
EXPERIÊNCIAS DE ESTUDANTES DE PSICOLOGIA AO CONDUZIR GRUPOS COM OUTROS UNIVERSITÁRIOS
}

\author{
Experiences of Psychology undergraduate students in conducting groups with other university stu- \\ dents
}

Experiencias de estudiantes de Psicología al conducir grupos con otros universitarios

SHIRLEY MACÊDO

Melina Pinheiro Gomes de Souza

ANa Lícia Pessoa NunEs

\begin{abstract}
Resumo: O objetivo desta pesquisa foi compreender experiências de processos envolvidos na prática da escuta clínica de estudantes de Psicologia ao conduzir grupos interventivos com outros universitários, buscando: descrever sentidos dessas experiências para a formação desses estudantes; apontar atravessamentos envolvidos; identificar possíveis conhecimentos, habilidades e atitudes desenvolvidos, assim como desafios enfrentados e ganhos de aprendizagem obtidos. Em uma perspectiva fenomenológica interventiva, utilizou-se o método da hermenêutica colaborativa. Durante 14 encontros de supervisão, foram colaboradores uma psicóloga, uma docente e oito estudantes de Psicologia que conduziam dois grupos interventivos com universitários. O instrumento utilizado foi a Versão de Sentido e os resultados levaram a concluir, principalmente, que os estudantes: vivenciaram um processo de crescimento pessoal e desenvolvimento profissional, permeado por um encantamento pela Psicologia; estiveram atravessados pelas realidades psicossociais dos universitários atendidos, mas conseguiram, atentos aos próprios limites, reconhecer a necessidade de um processo pessoal e internalizar as bases de uma matriz de identidade profissional; aprenderam a sistemática do método, sendo as supervisoras e os colegas essenciais no processo de aprimoramento da escuta. Destaca-se, portanto, a necessidade de redes de apoio para os universitários e melhorias no processo de capacitação do estudante de Psicologia, visando seu futuro ingresso no mercado de trabalho.
\end{abstract}

Palavras-chave: Escuta; Sofrimento Universitário; Formação do Psicólogo; Serviço Escola; Pesquisa Fenomenológica.

\begin{abstract}
This research aimed to understand the experiences of processes in the clinical listening of Psychology undergraduate students in conducting intervention groups with other university students, seeking to describe the meanings of these experiences for the formation of these students; point out crossings involved; identify possible knowledge, skills and attitudes developed, the challenges faced and the learning gains. In an interventional phenomenological perspective, the method of collaborative hermeneutics was used. In 14 supervisory meetings, collaborators were a psychologist, a professor and eight psychology undergraduate students conducting two intervention groups with university undergraduate students. The instrument used was the Version of Sense and the results indicated that the students experienced personal growth and professional development, were enchanted by Psychology; and crossed by the psychosocial realities of the students attended, but managed, with their own limits, to recognize the need for a personal process and to internalize the basis of a professional identity matrix; they learned the method systematics; supervisors and colleagues were essential in the process of improving listening. Therefore, stand out the need for support networks for university undergraduate students and improvements in the qualification process of the Psychology student, aiming at their future entry into the job market.
\end{abstract}

Keywords: Listening; University Suffering; Formation of the Psychologist; School Service; Phenomenological Research.

Resumen: El objetivo de esta investigación fue comprender experiencias de procesos involucrados en la práctica de la escucha clínica de estudiantes de Psicología al conducir grupos intervencionistas con otros universitarios, buscando: describir sentidos de esas experiencias para la formación de esos estudiantes; apuntar atravesamientos involucrados; identificar posibles conocimientos, habilidades y actitudes desarrollados, desafíos y ganancias de aprendizajes obtenidas. En perspectiva fenomenológica intervencionista, se utilizó el método da hermenéutica colaborativa. Durante 14 encuentros de supervisión, colaboraron una psicóloga, una docente y ocho estudiantes de Psicología que conducían dos grupos intervencionistas con universitarios. Se utilizó la Versión de Sentido y los resultados llevaron a concluir que los estudiantes: vivenciaron un proceso de crecimiento personal, desarrollo profesional, permeado por encantamiento por la Psicología; atravesados por las realidades psicosociales de los universitarios, pero consiguieron, atentos a los propios límites, reconocer la necesidad de un proceso personal e internalizar las bases de una matriz de identidad profesional; aprendieron la sistemática del método, siendo las supervisoras y los compañeros esenciales en el proceso de mejoramiento de la escucha. Se destaca la necesidad de redes de apoyo para los universitarios y mejoras en el proceso de capacitación del estudiante de Psicología, visando su futuro acceso al mercado laboral.

Palabras clave: Escucha; Sufrimiento Universitario; Formación del Psicólogo; Servicio Escuela; Investigación Fenomenológica. 


\section{Introdução}

A partir de 1990, a clínica em Psicologia vem se ampliando como um dado ethos, um lugar de acolhimento ao sofrimento, independente da área de aplicação e prática do psicólogo, que pauta suas intervenções comprometido "com a escuta do interditado e a sustentação das tensões e dos conflitos” (Figueiredo, 1995, p.40). Focados no cuidado de alguém em situação de sofrimento (Macêdo, 2015), os fazeres do psicólogo na contemporaneidade se constituem como clínica social (Romagnoli, 2006) e ampliada (Campos, 2003), sendo ofertados à comunidade serviços não restritos à psicoterapia em consultório privado. Assim, a clínica invade organizações, hospitais, escolas ou quaisquer instituições onde se possa promover saúde mental, seja individual ou coletivamente.

Sobre isso, Lima et al. (2013) enfatizaram que as mudanças em políticas públicas no âmbito da saúde mental no Brasil, na primeira década do século XXI, assim como novas diretrizes para a formação graduada em Psicologia, levaram os serviços escola a repensarem suas ofertas de atendimentos frente aos deslocamentos da prática do psicólogo.

As práticas clínicas contemporâneas em Psicologia, portanto, não mais se limitam a acompanhamentos psicoterapêuticos individuais, mas se ampliam a intervenções grupais para prevenção e promoção da saúde do sujeito integral (Pereira, 2013), nas quais predominam atividades inter e multidisciplinares, rompem-se limites de técnicas clínicas tradicionais e disponibilizam-se à clientela outros dispositivos de cuidado.

Frente essas mudanças, em serviços escola de Psicologia, o conceito de transversalidade, tão rico à proposta da clínica ampliada, passa a ser considerado. Trata-se de um dispositivo de cuidado pelo qual o profissional de saúde deve atentar para e atuar na rede de relações em que o sujeito que demanda ajuda e ele mesmo estão inseridos, assumindo o espaço público da realidade psicossocial mais ampla, assim como considerando a produção de subjetividades e saberes no cotidiano de sua prática (Ferreira Neto, 2008).

Nesses serviços, um dos desafios enfrentados na produção de subjetividades atravessadas pela realidade social parece ser os que envolvem demandas de usuários universitários de diversos cursos, algo já enfatizado por Peres, Santos e Coelho (2003, 2004). Esses sujeitos, por se encontrarem em sofrimentos de várias ordens (como, por exemplo, os relacionados à distância de casa e à adaptação à vida acadêmica), não conseguem elaborar estratégias de enfrentamento, muitas vezes perdendo o sentido da vida diante das pressões contemporâneas (Macêdo, 2018).

Ribeiro e Bolsoni-Silva (2011) já haviam destacado a importância de um serviço de Psicologia para evitar abandono dos cursos e problemas de saúde mental. O jornal Estado de São Paulo (Cambricoli \& Toledo, 2017) enfatizou recentemente o aumento de transtornos mentais nesta categoria estudantil. Já Castro (2017) argumentou que uma pluralidade de fatores afeta os processos de aprendizagem, adaptação, formação e desenvolvimento psicológico dos discentes; defendendo que a experiência acadêmica pode se constituir como um desafio ao universitário, pois influencia nos relacionamentos interpessoais com colegas, professores, outros integrantes das Instituições de Ensino Superior (IES), nos propósitos de vida e nos objetivos profissionais e crescimentos pessoais. Por sua vez, Graner e Ramos Cerqueira (2017) apontaram fatores de risco enfrentados por universitários na contemporaneidade, quais sejam: distância da família, adaptação à cidade e à vida acadêmica, vulnerabilidade social e psíquica, condições adversas de pressões contemporâneas para se manter estudando, ansiedade frente ao futuro ingresso no mercado de trabalho etc.

Diante desses fenômenos, as IES começam a repensar a problemática, implementando ações a fim de favorecer condições psicológicas para a formação escolar desses sujeitos. Portanto, considerando-se fatores de risco como demandas em serviços escola de Psicologia, acredita-se que uma pesquisa voltada à formação do estudante de Psicologia em processos de grupos interventivos com outros universitários que compartilham da mesma realidade social que eles, estará contribuindo para a melhoria dos serviços prestados, assim como para elaboração de fatores de proteção.

Necessariamente pensar nesses serviços leva a refletir, também, sobre processos de formação profissional em cursos de Psicologia. Estudos sobre formação profissional, desenvolvimento de competências e carreira no ensino superior vêm ganhando espaço nos últimos anos (por exemplo, Gondim, Morais \& Brantes, 2014; Monteiro, Sobrosa, Dalagasperina \& Dias, 2016; Soares, Souza, Monteiro \& Wolter, 2018). No tocante à formação de psicólogos, acredita-se, como propõem Macêdo, Souza e Lima (2018), que a escuta seja uma competência a ser desenvolvida, visando melhores serviços prestados à sociedade e preparação mais efetiva para o futuro mercado de trabalho. Além disso, sendo a temática "sofrimento psíquico do universitário" uma questão de saúde pública (Oliveira \& Padovani, 2014), considera-se a possibilidade de impasses enfrentados por estudantes de Psicologia quando prestam serviços a outros universitários.

Lançando-se ao desafio de ajudar a quem compartilha da mesma realidade social, posto que vivencia experiências semelhantes, seja na universidade, seja fora dela, os futuros psicólogos devem ter, ao seu dispor, uma efetiva rede de apoio que, necessariamente, passa pela ordem do acompanhamento psicológico pessoal e da 
supervisão sistemática, para cuidarem das suas capacidades de cuidar.

Segundo Tavora (2002), a supervisão tem, além do objetivo de transmitir ensinamentos básicos, o de facilitar com que o estudante olhe para dentro de si, para o cliente, para sua relação com esse e para o vínculo com o supervisor. Principalmente, no que se refere a acompanhamentos grupais por estudantes de Psicologia, supervisionar é inserir esse treinando "em um mundo de relações reais e presentes, onde ele pode avaliar-se, espelhar-se e encontrar com o outro" (p.121).

Por sua vez, Rocha, Silva, Barbosa e Duarte (2013) defenderam que as intervenções em grupo, justamente pela importância da experiência interpessoal e da participação dos pares e do supervisor na construção da identidade do estudante de Psicologia, são bastante profícuas na promoção do desenvolvimento profissional do aprendiz. As autoras chegaram a essa conclusão porque desenvolveram um programa de capacitação em grupo com graduandos em Psicologia, visando um processo de "tornar-se psicólogo para além das aulas”, e constataram, dentre outros resultados, que os mesmos passaram por mudanças significativas nos seus processos de autoconhecimento, capacidades de reflexão, capacidades de aceitar e lidar com o desenvolvimento profissional. Adicionalmente, conscientizaram-se do papel do psicólogo, o que favoreceu padrões de autoavaliação e autorresponsabilização, além da vivência de um sentido único e fiel de si mesmos como pessoas e futuros profissionais.

Diante do exposto, a presente pesquisa foi pensada a partir dos seguintes questionamentos: como se dão os processos envolvidos na prática da escuta clínica de estudantes de Psicologia em grupos interventivos com outros universitários? Qual o sentido que esses grupos têm no processo de formação de estudantes de Psicologia? Quais atravessamentos estão envolvidos nesses processos? Que possíveis conhecimentos, habilidades e atitudes são desenvolvidos? Quais desafios são enfrentados e quais os ganhos de aprendizagem são obtidos por estudantes de Psicologia nessas intervenções?

Acredita-se que uma pesquisa intervenção que busque responder esses questionamentos tem a vantagem de promover processos de transformação dos sujeitos, da realidade e do contexto onde eles estão inseridos, pois se compreende, como propõem Sarmento e Casagrande (2014), que uma prática sistemática focada na saúde mental convoca sujeitos e instituições a uma reflexão crítica coletiva, já que, por possuir uma dimensão política, permite às pessoas repensarem e mudarem seus modos de subjetivação e práticas cotidianas.

Nesse sentido, o objetivo geral do presente estudo foi compreender experiências de processos envolvidos na prática da escuta clínica de estudantes de Psicologia ao conduzir grupos interventivos com outros universitários. Como objetivos específicos, buscou-se: descrever os sentidos dessas experiências para a formação dos estudantes de Psicologia; apontar atravessamentos envolvidos; identificar possíveis conhecimentos, habilidades e atitudes desenvolvidas, assim como desafios enfrentados e ganhos de aprendizagem obtidos por esses sujeitos.

\section{Método}

A pesquisa, desenvolvida com o apoio do Programa de Bolsas de Iniciação Científica (PIBIC CNPq/UNIVASF 2018-2019), respeitou os preceitos éticos das Resoluções CNS/MS 466/2012 e 510/2016, estando registrada sob CAAE 88562318.2.0000.5196 e aprovada pelo parecer N. ${ }^{\circ}$ 2.759.228, emitido pelo Comitê de Ética em Pesquisa da Universidade Federal do Vale do São Francisco (UNIVASF).

Sendo o estudo fundamentado na Psicologia Humanista, optou-se pela abordagem qualitativa, na qual o conhecimento é construído de acordo com as realidades que são próprias de sujeitos inseridos em determinados grupos sociais. Por focar em sentidos e significados da experiência humana para quem as vivencia, tratou-se de uma pesquisa fenomenológica, na qual se é considerado o encontro dialógico entre pesquisador e pesquisado, almejando-se uma compreensão fundamentada na análise da intersubjetividade.

Halling e Leifer (1991) foram autores pioneiros nas propostas em pesquisa dialógica, articulando prática clínica e de pesquisa para favorecer a educação em estudantes de Psicologia. Posteriormente, Finlay (2009) apresentou uma abordagem relacional à fenomenologia, mais especificamente um método de pesquisa centrado na relação, para psicoterapeutas, buscando atender a quatro dimensões interligadas: presença aberta, intersubjetividade corporificada, cocriação dialógica e Eus entrelaçados. Nesse sentido, reconheceu o poder do diálogo em pesquisa fenomenológica, onde a relação pesquisador e pesquisado faz emergir os dados, que são cocriados em um encontro intersubjetivo de mútua afetação.

Considerando-se, portanto, perspectivas mais recentes em pesquisa fenomenológica interventiva e colaborativa, no presente estudo optou-se pela proposta de Macêdo (2015), a hermenêuticacolaborativa, um método de pesquisa e intervenção, criado no bojo da clínica humanista-fenomenológica do trabalho, mas utilizado em outros contextos de pesquisas e práticas psicológicas.

A hermenêutica colaborativa é embasada filosoficamente em Merleau-Ponty e Gadamer, e teoricamente em Carl Rogers. Compreendendo que profissional e cliente estão envolvidos numa mesma reciprocidade de perspectivas, considera os preceitos merleau-pontyanos de intersubjetividade e redução fenomenológica parcial (epoké incompleta). Prescreve, também, como propõe Gadamer, que em 
um contexto de diálogo, sujeitos compartilham de uma mesma realidade social e podem, em um jogo de perguntas e respostas, argumentos e contraargumentos, resgatar suas tradições e chegarem a um novo consenso sobre os sentidos da experiência tematizada. Em adição, fundamenta-se no preposto por Carl Rogers quanto aos princípios norteadores da Abordagem Centrada na Pessoa e às atitudes facilitadoras para um clínico em Psicologia consideração positiva incondicional e autenticidade - no sentido de que tais atitudes viabilizam mudanças em modos de subjetivação (sentir, pensar e agir) dos envolvidos em um processo.

Conceitualmente, o método consiste em uma ação criativa de produção de significados, na qual os sujeitos se engajam e, encarnados que estão no mundo, compartilham experiências pela intercorporeidade, produzindo novos sentidos.

Foram colaboradores da pesquisa oito estudantes de Psicologia (duas estagiárias e seis extensionistas) facilitadores de grupos interventivos com universitários, uma psicóloga e uma docente, supervisoras desses estudantes, que adotavam a perspectiva humanista-fenomenológica em suas práticas, abordagem para a qual a escuta ativa do processo do cliente envolve, necessariamente, uma autorreflexão constante por parte do psicólogo em formação, principalmente estudantes em início de prática. Uma supervisão nesses parâmetros, sem haver distorção do papel do supervisor, que não é psicoterapeuta do supervisionando, considera este como um sujeito que muda nas práticas interventivas que conduz, reconhecendo, portanto, a necessidade do desenvolvimento de competências para uma ação clínica eficaz (Mesquita \& Carvalho, 2014).

Utilizou-se como instrumento de coleta de dados a Versão de Sentido (VS), proposta por Amatuzzi (1991), um relato breve, escrito imediatamente após um encontro, onde o sujeito registra o que de mais significativo para ele ocorreu. Ao ser lida em um encontro, favorece versar e conversar sobre uma experiência, até chegar à explicitação compartilhada do sentido e dos significados vividos. Neste estudo, foi solicitado aos colaboradores, autores das VS's, que as lessem no encontro posterior ao de sua escrita, sendo o diálogo suscitado pela leitura a base para um compartilhar de significados da experiência. Esses significados eram explorados ao longo dos processos de supervisão dos quais eles participaram. Como bem enfatizou Amatuzzi (2008, p.84): “A VS 'traz' seu autor, traz seu projeto, dá-lhe a conhecer nesse novo contexto de interlocução. E esta é, justamente, uma das finalidades da supervisão”.

Foram promovidos dois grupos de supervisão, referentes a processos de dois grupos interventivos com universitários, conduzidos, cada um, por uma dupla de estudantes de Psicologia. O primeiro grupo pesquisado tinha oito estudantes de Psicologia, o segundo tinha cinco, que também participaram do primeiro grupo, sendo as supervisoras as mesmas para ambos os grupos. Cada processo de supervisão se deu em sete encontros, nos quais, com exceção do primeiro, o tempo era dividido, parte para a leitura e exploração de VS's do encontro anterior, parte para supervisão do grupo interventivo e, nos cinco minutos finais, a solicitação de escrita das próximas VS's, que eram lidas no encontro posterior e, assim, sucessivamente, até o último, quando a VS produzida foi lida nesse próprio encontro.

As VS's foram analisadas fenomenologicamente a partir dos seguintes passos (Amatuzzi, 2009; Macêdo, 2015):

a) Leitura integral/contato com o todo: leitura da VS por cada colaborador, para que os membros da equipe de supervisão alcançassem os significados da experiência.

b) Presentificação do sentido da VS: os colaboradores procuravam entrar em consenso sobre o sentido de cada VS, que apenas era validado pelo colaborador que a escreveu.

c) Síntese de cada encontro de grupo de supervisão: ao final do processo de supervisão, a equipe de pesquisa dispunha todas as VS's de um encontro numa planilha e, levando em consideração sentidos em comum, escrevia em linguagem psicológica o processo vivido pelo grupo naquele encontro. Fez isso para os 14 encontros realizados.

d) Síntese do processo grupal: após a síntese de cada encontro, a equipe de pesquisa buscou compreender o processo vivido por cada grupo de supervisão ao longo dos encontros, escrevendo um texto que consistiu na devolutiva para encaminhar aos colaboradores, que a liam, podendo alterar, manter ou mesmo negar a análise realizada.

Para efeito de análise das experiências investigadas, atribuíram-se aos estudantes de Psicologia pseudônimos referentes a pedras preciosas. Considerando que essas, quando são encontradas ligadas a outros minerais, para serem separadas, precisam ser lapidadas (Valhalla, 2018), às supervisoras foram atribuídos pseudônimos referentes a processos de lapidação. Assim, foram nomeados os estudantes de Ágata, Jade, Jaspe, Ônix, Pérola, Rubi, Safira e Turquesa; e as supervisoras de Brilhante e Cabochon.

Vale salientar que a descrição da experiência investigada será apresentada de forma a entrelaçar os objetivos pretendidos, visto que nas VS's, e seus respectivos sentidos produzidos pelos colaboradores durante os encontros, aglutinavam: atravessamentos envolvidos; conhecimentos, habilidades e atitudes desenvolvidas; desafios enfrentados; e ganhos de aprendizagem obtidos. Também é importante destacar que os grupos de universitários foram acompanhados por diferentes duplas de estudantes de Psicologia e que cinco dos estudantes participantes do primeiro grupo de supervisão também estavam no segundo grupo. Isso 
favoreceu, resguardadas as diferenças do que cada um vivenciou, que eles estivessem diante de um processo de contínuo amadurecimento, até porque não foram grupos de universitários que ocorriam ao mesmo tempo, mas que se seguiram um ao outro. Assim, não se buscará semelhanças e diferenças entre, por exemplo, o primeiro encontro de um e do outro grupo de supervisão, mas se descreverão os processos considerando os 14 encontros promovidos. Além disso, não se concebe que seja necessário diferenciar depoimentos de estagiários e estudantes extensionistas, tendo em vista a análise está focada nos compartilhamentos de sentidos em comum sobre a experiência vivida ao longo dos encontros.

\section{Resultados e Discussão}

No primeiro encontro do primeiro grupo de supervisão houve, entre os estudantes, um sentimento de estar em processo de construção e crescimento pessoal como profissional humanizado que precisava regar a formação com o coração. Destacaram que, para que isso ocorresse, seria necessário que houvesse entrega de si mesmos para viver e entender as próprias emoções que afloravam. Refletiram sobre passado e presente, sobre o eu e os outros, em um processo de ressignificação da própria prática como futuro profissional e do lugar que se encontravam: o de se moldar e aprender sobre sensibilidade. Consideraram que estavam experienciando um processo novo de construção/ aprendizado como sujeitos. Um processo que afetava, transbordava, surpreendia, saltava aos olhos; que era estranho, mas tinha sentido; que era intenso e lindo de acompanhar; que dava esperança para perceber coisas boas em tempos difíceis. Ao final do encontro, havia o sentimento de gratidão, esperança, alegria de estar junto à equipe e participando do processo de construção de uma universidade mais humana e com qualidade de vida.

Nesse encontro, pôde-se perceber como a prática da escuta clínica permitiu a esses estudantes uma abertura à experiência de crescimento pessoal e consequente processo inicial de identificação como futuros psicólogos. A experiência fazia sentido porque conseguiam compreender não só a realidade social enfrentada pelos universitários acompanhados, mas porque perspectivavam, a partir da prática psicológica oferecida, uma possibilidade de humanizar e oferecer qualidade de vida à universidade em que estudavam e atuavam. Vejamse, as VS's abaixo:

Uma palavra que resume tudo que escutei hoje é construção. Senti-me contemplada e afetada com os relatos, com os desenhos e as interpretações. É tudo novo para mim, por isso também é construção. Construção de algo diferente para mim, de novas experiências e de muito crescimento, mas construção não só para mim, mas para os outros. Construção de uma universidade mais humana e de alunos com qualidade de vida melhor (Rubi).

O ontem e o hoje. Vários "Eus" de mim, como pessoa, como profissional, se moldando, ressignificando, e isso é lindo de se acompanhar. Tanto aprendizado que não cabe em mim! Transborda e afeta e me salta aos olhos! Também os deixa marejados. (Pérola)

O processo vivido por esses colaboradores, nesse encontro, remete às ideias de Ziliotto, Benvenutti, Matiello e Peil (2014) que, ao estudarem concepções e expectativas de estudantes de Psicologia sobre sua futura profissão, constataram que os mesmos, com certo encantamento e elogios, reconheceram as potencialidades da profissão e a associaram à condição de ajuda.

Já no segundo encontro, os estudantes refletiram sobre questões da vida pessoal ao compartilhar das questões dos outros universitários, quando reconheceram que, às vezes, na prática da Psicologia, o caminho do outro também é o mesmo que o seu. E, apesar do caos e da sensação de que o tempo estava corrido, havia evolução e mudança. Isso, segundo eles, requeria respeito à subjetividade e ao seu tempo e ao do outro, assim como percepção de que o caminho poderia ser simples, instigante e encantador. Para tanto, refletindo sobre como se descentrar de si para abrir espaço para o outro, seria necessário que eles apreciassem esse caminho; reconhecessem o que era possível ser feito em meio aos obstáculos; assim como estivessem preparados ao inesperado e à perda de controle.

Esse processo da tomada de consciência de que o que se passa com o outro é semelhante ao que se passa consigo parecia promover um caos interno, diante da possibilidade da perda de controle e do obstáculo da indiferenciação. Como defende Tavora (2002), aqui, o papel do supervisor é decisivo para que os estudantes de Psicologia compartilhem suas dúvidas, inquietações, podendo contar com a acolhida do supervisor. No entanto, é possível perceber, pelas VS's dos colaboradores dessa pesquisa, que se abrir a essa experiência e respeitar o seu tempo e o tempo do outro é essencial para reconhecer o que pode ser feito, enquanto as supervisoras refletiram como essa tomada de consciência é importante no processo de tornar-se psicólogo e servir ao outro:

Às vezes o caminho do outro é o nosso caminho também (Jade).

O processo de evolução requer tempo. Também é preciso ter respeito pela subjetividade do outro. Tensionar e acalmar no tempo certo (Pérola). 
O processo é evolução. Mas como se descentrar em si para abrir espaço para todos? Eis o processo de tornar-se psicólogo: recriar-se, todos os dias, para servir ao outro (Brilhante).

Posteriormente, no terceiro encontro, houve reflexão sobre o tempo e o que ele ensina sobre a busca constante de si mesmo. Nesse processo, para os colaboradores, haveria avanços e receios, abertura, criatividade e reconhecimento dos limites, mas também aprendizagem com o outro e com o novo. Para eles, seria através do tempo, e de si mesmo vivendo no tempo, que se poderia acreditar na possibilidade de construir e reconstruir tudo, e cada um tem uma forma diferente de reagir a uma mesma situação. Portanto, às vezes, se reconhecer como frágil, mesmo sendo uma tarefa difícil, é necessário para o processo de evolução. Evolução que pode ocorrer em tempos diferentes, seja através do tempo cronológico ou tempo de maturação. Os estudantes acreditavam que a sabedoria não obedece a um tempo cronológico, vem do próprio processo histórico e merece ser reconhecida e validada. Escreveram que se tratava de um processo de construção que requeria movimento entre o ir e o vir, entre passado e presente, entre encontros e desencontros: uma inconstância na busca de ser em constante movimento de (re)criar-se.

Avanços e receios, abertura e criatividade. Reconhecimento de limitação, aprendizagem com o outro, com o novo. Pés enraizados precisam de expansão (Ágata).

Cada um tem uma forma diferente de reagir a um mesmo ambiente. Se demonstrar forte muitas vezes é sinal de fraqueza, se reconhecer como frágil é tarefa difícil, mas necessária para que, aos poucos, possamos evoluir (Rubi).

\section{(Re)criar-se (Jaspe).}

Parece, portanto, pelas VS's acima, que os estudantes viveram um processo de desenvolvimento pessoal como condição para o desenvolvimento profissional, como já enfatizavam Tambara e Freire (1999). Isso está coerente com a perspectiva humanista em Psicologia. Pode-se, também, arriscar dizer que os colaboradores da pesquisa pareceram passar por uma trajetória de tornarem-se si mesmos, avaliando passado e futuro, o que pode constituir um processo de aprendizagem significativa (Rogers, 1997). Atentos à sua corrente experiencial, os colaboradores não se intimidaram em reconhecer, neles mesmos, características antes indesejadas, passando a ser mais flexíveis e maleáveis, entrando em contato com os próprios limites e respeitando a diferença do tempo de recriação de cada um.

Sem conseguirem diferenciar o processo de crescimento pessoal do desenvolvimento profissional, no quarto encontro, houve um movimento dos estudantes em repensar a própria vida e a prática profissional e refletir sobre a necessidade de ser maleável nesses processos, de modo que conseguissem olhar para si e para o outro mutuamente, reconhecendo que as imprevisibilidades e dificuldades também fazem parte do caminhar e do processo de tornar-se psicólogo. Escreveram sobre um processo de aprendizagem que requer: tempo, implicação com/ distanciamento do outro e equilíbrio para enxergar a beleza do caminho (que tem pedras, espinhos e dores, mas também flores, frescor e aromas). Realçaram que tudo é necessário para viver e enfrentar os obstáculos do dia-a-dia com sabedoria, prerrogativa reconhecida por uma das supervisoras. Vejam-se as VS's abaixo:

Hoje me coloquei dentro de um processo de repensar a prática e as minhas colocações em relação aos clientes. Sinto felicidade em saber que estou em um processo de aprendizado. Fazendo um comparativo, sinto que antes era apenas folhas largadas ao vento. Hoje, sinto que inicio um processo de florescer (Ônix).

É preciso ter calma para que a flor floresça. Dar tempo ao tempo para que a rosa seja capaz de desabrochar (Safira).

Equilibrar-se - eis a grande sabedoria de viver (Cabochon).

Parece que eles estavam, na metade do número de encontros de supervisão realizados, no meio de um processo de desenvolvimento profissional, considerando o nível de reflexão, autoavaliação, autoconhecimento e autorresponsabilização nessa vivência singular de encontro consigo mesmos como pessoas. Esse reconhecimento do próprio Eu vinha acompanhado de uma conscientização de como isso interferia na relação com o cliente, algo já proposto por Silva, Barbosa e Duarte (2013), quando tematizaram sobre o desenvolvimento da matriz de identidade profissional na formação do estudante de Psicologia.

Após esse encontro, o grupo parou para refletir sobre o processo de tornar-se psicólogo. Os estudantes reconheceram que, às vezes, não percebiam onde estavam, precisando de pausas e momentos de respirar para continuar. Então, lembraram a importância das dimensões do passado, presente e futuro no processo de aprendizagem: deveriam se conectar com o presente, reconciliando-se com o passado e construindo o futuro. Para isso, seria necessário sustentarem o silêncio para que as coisas pudessem fluir. Refletiram que esse processo pode ser árduo para sobreviver em meio às dificuldades 
da profissão, entretanto, o fato de estarem junto com outros reconfortava o processo de caminhar:

Se reconciliar com o passado e ficar em paz com o futuro. O futuro é construído aqui e agora, o presente é mais importante (Rubi).

Hoje o grupo nos lembrou de como é árdua nossa profissão. Mas a sinergia do grupo reacendeu a premissa de que teremos uns aos outros nesse processo. Sinceramente, é muito reconfortante (Jade).

Portanto, no quinto encontro de supervisão, foi ressaltado pelos colaboradores dessa pesquisa o papel dos colegas. Também, a partir da VS de Ônix, abaixo, compreende-se, claramente, a importância das supervisoras no processo, proporcionando, como enfatizam Espírito e Castro (2012), segurança para a atuação do estudante, o que viabiliza a internalização do papel profissional e colabora no processo de formação de identidade profissional.

Estar submetido a um processo de aprendizagem é estar receptivo à escuta supervisonada. Aquilo que antes fez sentido se torna passível de ressignificação (Ônix).

No sexto encontro, os colaboradores reconheceram que, em uma prática psicológica, encontrar com a diferença dos outros frustra, mas promove aprendizagem. Destacaram que seria preciso respeitar e compreender o tempo do outro, acreditando nos pequenos passos e movimento desse outro. Também seria necessário parar, dosar os próprios passos, equilibrar-se e recomeçar diante da tempestade desse processo de evolução. Por fim, ao sétimo encontro, referendaram seus processos de evolução como estudantes de Psicologia e o processo de acompanhamento psicológico dos universitários como transformadores e constitutivos de uma abertura a um recomeço. Versaram sobre compartilhar experiências na tempestade desse processo de metamorfose de encontro consigo e com o outro, de aceitação, de fluir. Reconheceram, ao final, na calmaria, que cada um tinha sua própria perspectiva, admitindo ser necessário considerar o que precisariam buscar e onde precisariam se desenvolver. Vejam-se:

Precisamos entender que o tempo é do SUJEITO! (Jaspe, $6^{\circ}$ encontro)

Que esforço reerguer após frustração! Quanta bagagem a ser levada e como encontrar e lidar com outras pessoas com outras bagagens (Ágata, $6^{\circ}$ encontro).

É autorrealizador ver como o indivíduo reconhece suas potencialidades, a partir das transformações que são, muitas vezes, invisíveis para si no início da terapia

(Turquesa, $7^{\circ}$ encontro).

Evoluir também é perceber e reconhecer as áreas e os aspectos em que preciso crescer (Rubi, $7^{\mathrm{O}}$ encontro).

Por essas VS's dos dois últimos encontros, é perceptível como eles estavam mais abertos ao outro e menos centrados em si, o que mostra como eles passaram, ao longo de todos encontros desse grupo, pelas três etapas propostas por Tavora (2002) para o desenvolvimento de estudantes em processos de supervisão de orientação humanista: inicialmente, precisando compreender a si mesmos (no contexto do desempenho de seu papel como facilitador dos grupos com outros universitários); em seguida, ensaiando se colocar no lugar do outro (mesmo que sem conseguir diferenciar-se devido ao compartilhamento de experiências em comum); e, ao final, sendo capaz de se envolver e tornando possível a experiência de encontro com esse outro.

Interessante, também, perceber como as supervisoras indicaram, pelas suas VS's, que parecem ter alcançado, ao final do processo desse primeiro grupo, o objetivo da supervisão, dando a compreender um sentimento de gratidão por isso:

Existe um tempo para cada coisa, tempo para plantar, tempo para colher, tempo para recomeçar, tempo para renascer... (Cabochon)

Chegar ao final é sempre o início de um novo começo. Onde vai dar? Saber esperar e dosar os passos é uma forma de garantir a caminhada (Brilhante).

No que diz respeito ao segundo grupo de supervisão, os estudantes de Psicologia perspectivaram o processo como possibilidade de ampliar o olhar sobre o processo grupal supervisionado para voltar a intervir com os universitários fluindo com mais autonomia. Alguns compreenderam que é possível criar folhas, crescer e, mesmo com dificuldades, florescer, apesar do sofrimento. Outros perceberam o encontro como uma recordação de um verso que possuía sentimentos como leveza, raiva, pressão, paz, harmonia, entre outros. Definiram o encontro, também, como um início ou recomeço. Enquanto as supervisoras experienciaram esse início como uma dualidade, devido à concepção de que o processo de supervisão estava próximo do fim.

Ver o grupo como grupo, fluindo e com autonomia. Mas ampliar a perspectiva ao voltar para o grupo com outro olhar (Ágata). 
O encontro de hoje recorda-me o seguinte verso de Eliane Stahl: às vezes, é difícil ser eu; nesses dias, fujo de mim; em outros, me confronto; nestes, me encontro (Ônix).

A dualidade de iniciar um grupo sabendo que o processo de supervisão está próximo do fim (Cabochon).

Parece, portanto, que a vivência do grupo anterior favoreceu aos estudantes enfrentarem a segunda experiência com mais leveza, paz e harmonia, apesar de ainda apresentarem sentimentos ambivalentes. Já se referiam a suas autonomias e reconheciam os erros e conquistas, algo que Tavora (2002) já enfatizou ao afirmar que, gradativamente, o estudante sob supervisão vai comparando suas vivências em diferentes momentos e avaliando seu próprio crescimento, o que, também, é observado pelo supervisor.

No segundo encontro desse grupo, eles perceberam que, mesmo com a distância em relação à realidade dos universitários atendidos, havia lugares em comum, onde os sentimentos se misturavam. $\mathrm{O}$ encontro foi, para alguns, algo confuso e de difícil concentração, enquanto, para outros, de reflexão sobre suas perspectivas. Entretanto, entenderam que, para sentir, é preciso perceber o próprio lugar e encarar as instabilidades:

Está em supervisão atualmente é como se me encontrasse frente a um espelho, porém, além do meu reflexo, vejo as perspectivas para além disso (Ônix).

É possível encontrar um lugar comum, mesmo à distância (Jade).

Pelas VS's escritas acima sobre esse encontro, é possível compreender como os estudantes de Psicologia estavam, paulatinamente, absorvendo os ensinamentos do método da hermenêutica colaborativa (Macêdo, 2015) e sua fundamentação merleau-pontyana no que se denomina de redução fenomenológica parcial, pois, diante do grupo de universitários, os estagiários pareciam estar em uma experiência de reciprocidade de perspectivas. Respeitando uma coerência metodológica de intervenção, eles parecem ter conseguido, em um processo de fusão de horizontes, fundamentado nas ideias de Gadamer (2003), diferenciarem-se e se abrirem ao mundo da vida compartilhado, ao mesmo tempo em que preservavam as singularidades envolvidas no processo.

Já no terceiro encontro, reconheceram que, mesmo diante do caos, dificuldades e bagunça, era possível aprender algo, ver uma saída e clarear a direção a seguir. Entretanto, também houve reflexão sobre o processo de compreender o todo, reconhecendo que olhar para ele é diferente de compreender as partes em separado. Além disso, refletiram que quando a cabeça está cheia, é necessário falar para evitar que os pensamentos se transformem em bagunça e o corpo trave em algumas situações.

\section{O caos também ensina (Jaspe).}

Aquilo que não falamos, que não demonstramos, acumula-se e transforma em bagunça (Turquesa).

\section{Todo labirinto tem uma saída (Ágata).}

Interessante que eles começam a perceber a importância de compartilhar sentidos com os outros, abrindo-se ao diálogo gadameriano para produzir novos sentidos, o que é de suma importância na sistematização do método para o qual estavam sendo treinados no grupo de supervisão: a hermenêutica colaborativa. Pensa-se assim porque, para Gadamer (2003), numa conversa, o entendimento hermenêutico é mais dialógico e interativo quanto mais houver uma versão coletiva do entendimento, já que a compreensão é participativa, conversacional e dialógica. A VS de Rubi nesse encontro parece representar isso: "O tudo tem um significado totalmente diferente das partes separadas. Hoje ficou tudo muito claro".

No quarto encontro, porém, houve reflexão sobre a importância de saber reconhecer os próprios limites, tendo os estudantes reafirmado, a partir disso, a necessidade do autocuidado, diante da responsabilidade, das possibilidades e dos obstáculos frente ao outro que busca ajuda. No entanto, no encontro seguinte, apesar de terem reconhecido, novamente, a necessidade de autocuidado, questionaram se, ao se depararem com os próprios limites e os do outro, saberiam reconhecê-los. Além disso, refletiram sobre a importância de parar para reorganizar-se, algo que demandaria maturidade para deixar para trás, levar para frente e refazer o caminhar. Para tanto, seria necessário vigiar as atitudes, ações e sentimentos. Esse processo, ocorrendo de maneira apressada, poderia represar.

Fluidez. A aprendizagem em todas as situações, além de reafirmar a necessidade de autocuidado (Ágata, $4^{\circ}$ encontro).

A pressa represa o outro (Jade, $4^{\circ}$ encontro).

Às vezes, precisamos vigiar nossas atitudes, sentimentos e ações, de modo que tenhamos noção quando for preciso reciclar (Turquesa, $5^{\circ}$ encontro). 
Ter discernimento diante das nossas escolhas e uma percepção mais apurada para a necessidade de autocuidado (Ônix, $5^{\circ}$ encontro).

Compreende-se, portanto, que os colaboradores parecem ter vivido um processo de amadurecimento para reconhecer a necessidade de passarem por um processo pessoal, o que, ao que tudo indica, a experiência prática pôde despertar de uma maneira mais concreta. Dentre tantos estudos sobre o assunto, a pesquisa desenvolvida por Kichler e Serralta (2014) constatou essa relação entre a experiência prática na formação graduada de estudantes de Psicologia e o reconhecimento deles da necessidade de um processo pessoal. Escreveram os autores: "o processo do estudante se conhecer, compreendendo seus limites e possibilidades, auxilia na identificação de sentimentos e comportamentos suscitados pelos atendimentos, e a capacidade de discernir entre seus movimentos emocionais daqueles dos pacientes" (p. 61). Aqui, novamente, destaca-se o papel do supervisor. Brilhante, nesse encontro, percebendo esse processo de amadurecimento, registra em sua VS: "Refletir sobre deixar para traz, levar para frente e refazer o caminhar demanda maturidade".

Ao chegar ao sexto encontro, os estudantes discutiram como o rumo da vida pode ser modificado através de coisas simples, sem antecipação, apenas deixando acontecer diversas possibilidades diante da tomada de decisóes na estrada da vida, mesmo com desconforto e receios. Isso parece ser o resultado de que, mais amadurecidos, estão mais abertos à experiência. De acordo com os princípios da Abordagem Centrada na Pessoa, proposta por Carl Rogers, a abertura à experiência é uma prerrogativa a uma filosofia de vida de quem trabalha a partir desses ensinamentos (Macêdo, 2015). Vejam-se VS's abaixo, nas quais, inclusive, uma das supervisoras admira o processo vivido pelas supervisionandas presentes naquele dia:

Tudo pode ser simples, não há necessidade de antecipação, deixa acontecer (Ágata).

Como simples coisas do dia a dia podem modificar nosso rumo. A vida é uma estrada com várias possibilidades. E é lindo ver as meninas se modificando na estrada da vida (Cabochon).

Ao final dos encontros desse segundo grupo, os colaboradores refletiram sobre encerramento de ciclos, reconhecendo que o findar também é bonito e surpreendente. Diante disso, novas possibilidades foram pensadas. Mesmo percebendo os desafios que estariam por vir, eles referendaram necessitar construir novas perspectivas. Salientaram que o grupo de supervisão proporcionou a sensação de pertencimento e, mesmo tendo enfrentado dúvidas quanto às próprias escolhas, diante da oportunidade de cuidar dos universitários e serem cuidados na supervisão, reconheceram a beleza do vasto horizonte da Psicologia que sonharam. Novamente se compreende, aqui, o encantamento pela profissão, como pontuado anteriormente na descrição do processo do primeiro grupo.

Mais um ciclo se encerrando com novas possibilidades a serem pensadas (Turquesa).

Hoje tive a sensação de pertencimento, digo isso, porque tive um semestre conturbado, que me fez duvidar se teria feito a escolha certa, e pensar, até mesmo, em desistir e tentar construir uma nova perspectiva. Em alguns instantes, senti que estava afogando-me em meio a um mar de responsabilidades. Mas passado tudo isso, o núcleo, a equipe, a supervisão, me fizeram reafirmar a mim mesmo, ao começar o processo, o horizonte vasto e bonito da Psicologia que tanto sonhei. Sofria muito com a identificação das falas, mas entendi que a partir do caos e sofrimento de tantos universitários que vivenciam o meu mesmo contexto, tive que experimentar cuidar e ao mesmo tempo sentir o cuidado em minha própria pele. Nesse instante, percebo a importância e a significância da minha escolha e o quanto isso me faz feliz (Ônix).

Diante dessa descrição e compreensão minuciosa de cada encontro de supervisão nos dois processos vivenciados pelos colaboradores da presente pesquisa, pode-se resumir os resultados encontrados:

a) A experiência vivenciada, compartilhada e avaliada no processo de supervisão pelos colaboradores, parece ter tido o sentido para os estudantes de estarem em constante processo de crescimento pessoal e desenvolvimento profissional, permeado por um encantamento pela Psicologia, além do reconhecimento da importância dos colegas e das supervisoras.

b) Atravessados que estavam pelas realidades psicossociais compartilhadas com os universitários que atendiam, conectaram-se com o passado e com o futuro e, mesmo enfrentando o desafio inicial de indiferenciação com esses outros, aprenderam a lidar com a diferença dos mesmos em relação a eles, principalmente no que se refere ao respeito do tempo de cada um, mesmo que de maneira frustrante.

c) Ao internalizar o papel de psicólogo, refletiram sobre a importância do autoconhecimento e da autorresponsabilização nos grupos conduzidos por eles, inclusive, refletindo sobre o que precisavam desenvolver. Nesse sentido, reconheceram seus limites e suas fraquezas, mas também suas conquistas, passando a ser mais flexíveis e maleáveis para lidar com as imprevisibilidades, os obstáculos e as instabilidades. Abriram-se, portanto, à experiência 
e se conscientizaram da necessidade de um processo psicoterapêutico pessoal na busca do equilíbrio e do autoconhecimento. Refletiram sobre seus erros e sobre questões pessoais que eram impeditivas dos processos dos grupos conduzidos e enfrentaram os desafios com sabedoria, em um movimento constante de encontro consigo mesmos ao encontrarem com os outros para os quais prestavam ajuda.

d) Aprenderam, também, a lidar com o silêncio, terem mais autonomia e usar técnicas específicas de condução de grupos, o que, juntamente com tudo o que foi listado até aqui, favoreceu as bases para o início de uma construção da matriz de identidade como futuros psicólogos. Além disso, absorveram os ensinamentos pautados nos pressupostos teóricos de Carl Rogers, mais especificamente as atitudes de consideração positiva incondicional e autenticidade, base para a hermenêutica colaborativa, além de adotarem posturas coerentes com os postulados filosóficos que embasam esse método, principalmente no que concerne à intersubjetividade, à epoké incompleta e à conversação, empregando-as de maneira sistemática. Para exemplificar isso, vale repetir parte da VS de Ônix do último encontro do segundo grupo de supervisão, já transcrita acima: "Sofria muito com a identificação das falas, mas entendi que a partir do caos e sofrimento de tantos universitários que vivenciam o meu mesmo contexto, tive que experimentar cuidar e ao mesmo tempo sentir o cuidado em minha própria pele".

e) Nesse processo, o papel das supervisoras e dos demais colegas foi essencial, pois os estudantes revelaram um sentimento de pertencimento àquele grupo, quando lhes foi disponibilizado apoio, escuta ativa, sustentação de conflitos e reconhecimento. As supervisoras, inclusive, revelaram admiração pelo processo de aprimoramento da escuta dos estudantes.

\section{Considerações Finais}

Os resultados discutidos permitem dizer que os objetivos do presente estudo foram alcançados, sendo o maior desafio, à equipe de pesquisa, estar envolvida no processo de supervisão, tento, constantemente, que fazer esforço cognitivo e afetivo para penetrar na experiência e dela extrair conhecimento. No entanto, a própria natureza interventiva e colaborativa do método utilizado viabilizou que o estudo fosse conduzido sem colocar em risco seu rigor metodológico.

Destaca-se, contudo, que estar diante de estudantes de Psicologia que enfrentam realidades psicossociaissemelhantesaosclientesacompanhados requer que um psicólogo pesquisador e supervisor envolvido numa pesquisa colaborativa como essa tenha clareza de seu lugar e da responsabilidade de sedimentar seu papel nesse processo que, sem dúvida, não pode ser de psicoterapeuta dos estudantes, mas também não é o de um mero instrutor, pois se requer dele o compromisso social como educador e profissional. Propõem-se, assim, estudos que contemplem experiências de psicólogos docentes ao conduzir supervisão de grupos como os que foram aqui estudados, já que o foco da presente pesquisa foi o processo dos estudantes de Psicologia, sendo as VS's dos supervisores utilizadas para amparar os resultados encontrados.

Por fim, acredita-se que os resultados dessa pesquisa possam colaborar no sentido das IES adotarem ações preventivas durante a vida universitária dos acadêmicos; cumprir o proposto pelo Programa Nacional de Assistência Estudantil; criar redes de apoio ao universitário; e refletir sobre melhorias no processo de capacitação do estudante de Psicologia, visando seu futuro ingresso no mercado de trabalho da profissão.

\section{Referências}

Amatuzzi, M.M. (1991). O sentido-que-faz-sentido: uma pesquisa fenomenológica do processo terapêutico. Psicologia: Teoria e Pesquisa, 7(1), 1-12.

Amatuzzi, M.M. (2008). Por uma psicologia humana. São Paulo: Editora Alínea.

Amatuzzi, M.M. (2009). Psicologia fenomenológica: uma aproximação teórica humanista. Estudos de Psicologia, Campinas, 26(1), 93-100.

Cambricoli, F., \& Toledo, L.F. (2017). Aumento de transtornos mentais entre jovens preocupa universidades. O Estado de São Paulo, 16 Setembro 2017. Recuperado em abril de 2018, de http:// saude.estadao.com.br/noticias/geral,aumento-de-transtornos-mentais- entre-jovens-preocupa-universidades, 70002003562

Campos, G.W.S. (2003). A clínica do sujeito: por uma clínica reformulada e ampliada. In G.W.S. Campos (Org.), Saúde Paideia (pp. 51-67). São Paulo: Hucitec.

Castro, V.R. (2017). Reflexões sobre a saúde mental do estudante universitário: estudo empírico com estudantes de uma instituição pública de ensino superior. Revista Gestão em Foco, 9, 380-401. Recuperado em janeiro de 2019, de http://unifia.edu.br/revista_eletronica/revistas/ gestao_foco/artigos/ano2017/043_saude_mental.pdf.

CNS/CONEP (2012). Resolução N. 466, de 12 de dezembro de 2012. Recuperada em abril de 2017, de http://conselho.saude.gov.br/resolucoes/2012/reso466.pdf 
CNS/CONEP (2016). Resolução N.510, de 07 de abril de 2016. Recuperada em abril de 2018, de http://conselho.saude.gov.br/resolucoes/2016/ reso510.pdf

Espírito, A.C.O., \& Castro, P.F. (2012). Reflexões sobre a formação da identidade profissional em Psicologia. Revista Educação, 7(2), 40-55. Recuperado em maio de 2019, de http://revistas.ung. br/index.php/educacao/article/view/1137/1030

Ferreira Neto, J.L. (2008). Práticas transversalizadas da clínica em saúde mental. Psicologia: Reflexão e Crítica, 21(1), 110-118. doi: 10.1590/ $\underline{\text { S0102-79722008000100014 }}$

Figueiredo, L.C.M. (1995). Revistando as psicologias. Da epistemologia à ética das práticas e discursos psicológicos. São Paulo: EDUC / Petrópolis, RJ: Vozes.

Finlay, L. (2009). Ambiguous encounters: a relational approach to phenomenological research. Indo-Pacific Journal of Phenomenology, 9(1), 1-17. doi: $\underline{10.1080 / 20797222.2009 .11433983}$.

Gadamer, H-G. (2003). Verdade e método. Petrópolis, RJ: Vozes.

Gondim, S.M.G., Morais, F.A., Brantes, C.A.A. (2014). Competências socioemocionais: fator-chave no desenvolvimento de competências para o trabalho. Revista Psicologia Organizações e Trabalho, 14(4), 394-406. Recuperado em maio de 2019, de http://pepsic. bvsalud.org/scielo.php?script $=$ sci arttext\&pi$\mathrm{d}=$ S1984-66572014000400006\&lng=pt\&tlng $=$

Graner, K.M., \& Cerqueira, A.T.D.A.R. (2019). Revisão integrativa: sofrimento psíquico em estudantes universitários e fatores associados. Ciência \& Saúde Coletiva, 24, 1327-1346. doi: $\underline{10.1590 / 1413-81232018244.09692017}$

Halling, S., \& Leifer, M. (1991). The theory and practice of dialogical research. Journal of Phenomenological Psychology, 22(1), 1-15.

Kichler, G.F., \& Serralta, F.B. (2014). As implicações da psicoterapia pessoal na formação em Psicologia. Psico, 45(1), 55-64. doi: 10.15448/1980$\underline{8623.2014 .1 .12531}$

Lima, M.C.P., Martins, K.P.H., Rocha, L.P., Parente Jr, P.A., Castro, I.P., Pinheiro, N.M., \& Domingues, M. (2013). Arte e mediação terapêutica: sobre um dispositivo com adolescentes na clínica-escola. Revista Mal Estar e Subjetividade, 13 (3-4), 775-796. Recuperado em maio de 2019, de http:// pepsic.bvsalud.org/scielo.php?script $=$ sci arttext\&pid=S1518-61482013000200015\&lng = pt\&tlng=pt.
Macêdo, S. (2015). Clínica humanista-fenomenológica do trabalho. A construção de uma ação diferenciada diante do sofrimento no e por causa do trabalho. Curitiba: Juruá.

Macêdo, S. (2018). Sofrimento psíquico e cuidado com universitários: reflexões e intervenções fenomenológicas. ECOS: Estudos Contemporâneos em Subjetividade, 8(2), 265-277. Disponível em: http://www.periodicoshumanas.uff.br/ ecos/article/view/2844

Macêdo, S., Souza, G.W., \& Lima, M.B.A. (2018). Oficina de desenvolvimento da escuta: prática clínica na formação em psicologia. Revista da Abordagem Gestáltica, 24(2), 123-133. doi: 10.18065/RAG.2018v24n2.1.

Mesquita, A.C., \& Carvalho, E.C. (2014). A Escuta terapêutica como estratégia de intervenção em saúde: uma revisão integrativa. Revista da Escola de Enfermagem da USP, 48(6), 1127-1136. doi: 10.1590/S0080-623420140000700022

Monteiro, J.K., Sobrosa, G.M.P., Dalagasperina, P., \& Dias, A.C.G. (2016). Desenvolvimento e planejamento de carreira em universitários: um estudo exploratório. Revista Trabalho (En)Cena, 1(2), 145-161. Recuperado em maio de 2019, de https://sistemas.uft.edu.br/periodicos/index. php/encena/article/view/2879/9702

Oliveira, N.R.C., \& Padovani, R.C. (2014). Saúde do estudante universitário: uma questão para reflexão. Ciência \& Saúde Coletiva, 19(3), 995-996. doi: $\underline{10.1590 / 1413-81232014193.11042012}$

Peres, R.S., Santos, M.A., \& Coelho, H.M.B. (2003). Atendimento psicológico a estudantes universitários: considerações acerca de uma experiência em clínica-escola. Estudos de Psicologia, PUC-Campinas, 20(3), 47-57. doi: $\underline{10.1590 /}$ $\underline{\mathrm{S} 0103-166 X 2003000300004}$

Peres, R.S., Santos, M.A., Coelho, H.M.B. (2004). Perfil da clientela de um programa de pronto-atendimento psicológico a estudantes universitários. Psicologia em Estudo, Maringá, 9(1), 4754. doi: 10.1590/S1413-73722004000100007

Ribeiro, D.C., \& Bolsoni-Silva, A.T. (2011). Potencialidades e dificuldades interpessoais de universitários: estudo de caracterização. Acta Comportamentalia, 19(2), 205-224. Recuperado em Dezembro de 2018, de http://pepsic.bvsalud. org/pdf/actac/v19n2/a05.pdf.

Rocha, A.C., Silva, G., Barbosa, R., \& Duarte, C. (2013). Tornar-se psicólogo para além das aulas: grupo de desenvolvimento com estudantes de Psicologia. Análise Psicológica, 1(XXXI), 87102. Recuperado em maio de 2019, de http:// 
www.scielo.mec.pt/scielo.php?script $=$ sci_art$\underline{\text { text } \& \text { pid }=\text { S0870-82312013000100006 }}$

Rogers, C.R. (1997). Tornar-se pessoa. São Paulo: Martins Fontes.

Romagnoli, R. (2006). Algumas reflexões acerca da clínica social. Revista do Departamento de Psicologia - UFF, 18(2), 47-56. Recuperado em abril de 2017, de http://www.scielo.br/pdf/ rdpsi/v18n2/v18n2a04.pdf

Sarmento, D.F., \& Casagrande, C.A. (2014). Processos constitutivos das políticas educacionais no âmbito municipal: a pesquisa-ação colaborativa como postura epistemológica, metodológica e política. Práxis Educativa, Ponta Grossa, 9(2), 531-552. Recuperado em março de 2017, de http://www.revistas2.uepg.br/index.php/praxiseducativa

Soares, A.B.; Souza, M.S., Monteiro, M.C., \& Wolter, R.M.C.P. (2018). Concepções de estudantes sobre maturidade para a escolha da graduação em Psicologia. Estudos e Pesquisas em Psicologia, 18(3), 755-772. Recuperado em maio de 2019, de_https://www.e-publicacoes.uerj.br/index. php/revispsi/article/view/40447/28244.

Tambara, N., \& Freire, E. (1999). Terapia centrada no cliente: Teoria e prática. Um caminho sem volta. Porto Alegre: Delphos.

Tavora, M.T. (2002). Um modelo de supervisão clínica na formação do estudante de Psicologia: a experiência na UFC. Psicologia em Estudo, Maringá, 7(1), 121-130. doi: 10.1590/S1413$\underline{73722002000100015}$.

Valhalla (2018). O que são pedras roladas, brutas e lapidadas? Recuperado em maio de 2019, de https://blog.helenacristais.com.br/o-que-sao-pedras-roladas-brutas-e-lapidadas/.

Ziliotto, D.M., Benvenutti, J., Matiello, M., \& Peil, S. (2014). Concepções e expectativas de estudantes de psicologia sobre sua futura profissão. Gerais: Revista Interinstitucional de Psicologia, 7(1), 82-92. Recuperado em maio de 2019, de http://pepsic.bvsalud.org/pdf/gerais/v7n1/ v7n1a08.pdf.
Shirley Macêdo (ORCID: http://orcid.org/00000003-1619-2353). Doutora em Psicologia Clínica. Professora Associada da Universidade Federal do Vale do São Francisco (UNIVASF), lotada no Colegiado de Psicologia, colaboradora da Residência Multiprofissional em Saúde Mental, membro do Laboratório de Estudos Transdisciplinares em Saúde e Educação (LETRANS) e Coordenadora do Núcleo de Cuidado ao Estudante Universitário do Semiárido (NuCEU). Membro da Associação Brasileira de Psicologia Fenomenológica (ABRAPFE) e do GT ANPEPP "Fenomenologia, Saúde e Processos Psicológicos”. Endereço Institucional: Centro de Estudos e Práticas em Psicologia - CEPPSI/UNIVASF. Av. José de Sá Maniçoba, s/n, Centro, 56304-205 Petrolina, PE - Brasil. Email: mvm.shirley@gmail.com

Melina Pinheiro Gomes de Souza (ORDIC: $\underline{\text { http:// }}$ orcid.org/0000-0003-2254-9443). Graduanda em Psicologia pela UNIVASF. E-mail: melinasouuza@ gmail.com

Ana Lícia Pessoa Nunes (ORCID: http://orcid. org/0000-0002-1107-8431). Graduada em Psicologia pela UNIVASF. E-mail: analicia.pessoa@hotmail.com

Recebido em 22.10.2019

Primeira Decisão Editorial em 15.04.2020

Aceito em 21.04.2020 